\title{
Linguistic Landscape for Korean Learning: A Survey of Perception, Attitude, and Practice of Korean Beginners at a Korean University
}

\author{
Wenjin Qi \\ Yuncheng University, Yuncheng, China \\ Heng Zhang \\ Nanchang Normal University, Nanchang, China \\ Nadezda Sorokina \\ Woosong University, Daejeon, South Korea
}

\begin{abstract}
This study aimed to investigate the perception of, attitude to and practice of linguistic landscape for Korean learning among the international Korean beginners. A questionnaire as a self-assessment instrument was given to a group of $\mathbf{4 1}$ international university students with lower Korean language proficiency studying in a Korean university. The descriptive statistics indicated that for perception, although they pay attention to English the most, they could also notice Korean and Romanized Korean on the linguistic landscape (LL). They are positive to the $L L$ as authentic input for Korean learning in terms of attitude. What is more, they could use the $L L$ to enhance their Korean learning particularly in practicing pronunciation and enriching vocabulary, with relatively less practice on grammar checking. This study attested the previous studies concerning the $\mathbf{L} L$ as an authentic source for language learning on the one hand, and on the other hand, it showed that even without guidance from the teachers in formal settings, the students could also spontaneously use the LL to learn the Korean language in natural settings.
\end{abstract}

Index Terms - linguistic landscape, Korean language learning, perception, attitude, practice, input

\section{INTRODUCTION}

Linguistic landscape (LL hereafter) is an emerging field of applied linguistics focusing on language(s) "displayed and exposed in public spaces" (Shohamy \& Gorter, 2009, p.1). It is originally termed by Landry \& Bourhis’s seminal study in 1997 and specifically refers to various written language appears in "public road signs, advertising billboards, street names, place names, commercial shop signs, and public signs on government buildings in a given territory, region, or urban agglomeration" (Landry \& Bourhis 1997, p.25). Since then, a great number of scholars exhibit special interest in it and incorporate it into a wide range of theories and disciplines, containing and not limited in language policy, semiotics, literacy studies, applied linguists, communication, politics, sociology, anthropology, geography, urban studies, economics, architecture, as well as education (Shohamy \& Gorter, 2009; Van Mensel et al., 2016).

In the arena of education, the LL is bestowed theoretically with a special function as an out-of-classroom and additional input in language education particularly in second or foreign language learning (Cenoz \& Gorter, 2008; Gorter, 2018). Numerous studies (Dagenais et al., 2009; Clemente, Andrade \& Martins, 2012; Sayer, 2010; Rowland, 2013) have been conducted to attest to it as a legitimate source in enhancing language learning. However, it should be noted that the existing studies were conducted in classroom settings with formal language learners who were provided with systematic language instruction. And for those who often encounter the LL in the natural settings and who lack formal language instruction, what is their perception of the LL and to what extent will they use the LL to enrich their language learning is rarely touched.

In South Korea, by April 1, 2019, the number of registered international students in higher education has reached 160,165 (Min-seo \& Kim, 2019). These students hold various Korean proficiency studying in this country: some with little Korean (but required to attend the language center to gain formal language training for further study), some with intermediate to advanced proficiency (holders of TOPIK 4 or above) (are following the syllabus of the universities). In addition to those who may potentially be proficient Korean users and those who are already proficient ones, there is a special group in which some students are pursuing their master's or doctor's degree in certain universities. They were admitted into universities via English language proficiency (TOEFL or IELTS) but not Korean. In other words, they are advanced users of English but their Korean proficiency is low or very basic, which may be a big challenge for them to study or live inside or outside campus where Korean is the dominant language.

In this paper, we will focus on this "weak" group who are immersing themselves in a new language environment and simultaneously are striving to learn the target language (mainly by self-learning without formal training) in the 
university where the author studies. From the perspective of the LL as input for language learning, we hope to find out what their perception of the LL is and how they will make use of the LL for their Korean language learning. A survey will be conducted among a group of international students of various disciplines studying at a South Korean University. By discovering their attitudes and views to the LL, we also keep a hope that this case study can contribute to verifying the role of the LL as authentic input in the international students' language learning process in natural situations. In the paper, we will first review the literature of the LL pertaining to language learning, followed by a survey in the form of a questionnaire. After that results and discussion will be presented.

\section{LITERATURE REVIEW}

The exploration of perception regarding the LL in general education settings can be dated back to Landry \& Bourhis's (1997) seminal work on linguistic landscape. In that study, questionnaires about the perception of the LL were given to a group of about 2000 Francophone secondary education students in Canada. The result indicated that the LL could be perceived as "the most salient marker" (Landry \& Bourhis, 1997, p.45) showing ethnolinguistic vitality from the subjective perspective. In addition to perception, attitude and preference of the LL were added to Cenoz \& Gorter's (2011) study with a total of 191 university students in the Basque Country (Spain) and Friesland (the Netherlands). It was found that the students in these two multilingual areas perceive the LL varied as more bilingual (in the Basque Country) or as more monolingual (in Friesland). In the same vein, Chestnut, Lee \& Schulte (2013) used a narrative methodology to discover the perceptions of three undergraduate students engaged in a linguistic landscape project. They also found that the students, by noticing the linguistic patterns of urban signs, came to have a new perspective on the linguistic environment.

In terms of the LL in the context of second language acquisition (SLA), Gorter \& Cenoz (2004) asked more specific questions such as 'How is the linguistic landscape perceived by L2 users?', 'What is the role of the linguistic landscape as an additional source of language input in SLA?' and furthermore 'What attitudes do these L2 users have towards the linguistic landscape?'. They concluded that the LL or parts of the LL can potentially influence our knowledge about language and language use. Furthermore, they theoretically analyze such roles of the LL as providing an additional source of input, developing pragmatic competence, literacy skills, as well as multicompetence and reflecting symbolic and affective functions (Cenoz \& Gorter, 2008).

A theoretic analysis is by no means sufficient to convince the practitioners. For the real application of the LL in the pedagogy, Sayer(2010) did an LL-related project in Oaxaca (Mexico) with his students who investigated the purposes, intended audiences and different meanings of English on signs in a Spanish dominant environment. In this study, the LL was regarded as a pedagogical resource so that the students could learn to connect the language in the street to the language in the classroom. Similarly, Malinowski (2010) collaborated English learners in Korea with Korean learners at a university in the US via a virtual website to discuss Korean-English images from signs in the LL. It is positive that the LL can foster the learners' reading abilities, develop their fluency in the target language and enhance their motivation by using real places and activities. And not coincidentally, in an EFL setting of a Japanese university, Rowland (2013) researched with a bunch of 27 students who were asked to collect photos in the public and analyze English used on the signs by answering 'How and why is English used on signs in Japan?'. This study verified that pedagogical linguistic landscape projects can benefit EFL students in developing their symbolic skills and critical literacy skills, especially from authentic and contextualized multilingual input.

After reviewing the available research particularly the ones by Sayer (2010), Malinowski (2010) and Rowland (2013) (and of course many more not listed in this paper), we could find that whatever level the students were in, they benefited from participating certain LL-related research. In other words, it is with the instructor's mediation through the LL that the learners "can make intentional use of the relevant aspects of their linguistic environment" (Kim, 2017, p.69). While for the learners who have no guidance from their teachers and lack systematic language training, particularly the international students immersing in a new environment to strive to study and live, the issues of what is their perception of, attitude to and practice of the LL in their natural and informal language learning need to be further explored. Focusing on a small group of international students in a Korean university, this study aims to touch the following three research questions.

(1) What language will the international students pay attention to more (most)?

(2) What is their attitude toward the LL as authentic input to learn the Korean language?

(3) What do they do with the LL to aid their Korean language learning?

\section{Methodology}

\section{A. Subjects}

Due to limited access to approaching more international students, the authors only got the permission of 47 international students. Among whom there were 6 high-proficient Korean users, who are considered invalid sources, and therefore were excluded in this study. Eventually the participants in this study were 41 international students who enrolled in a Korean university (for limited access to involving ). There were 25 males and 16 females aging from 20 to 42. They are from different countries, among them were 20 Chinese, 5 Vietnamese, 4 Pakistani, 4 Uzbek, 3 Indian, 2 
Bangladesh, 1 Irani, 1 Japanese as well as 1 Russian. They went to this university to pursue a master's or doctor's degree and had various academic backgrounds including mechanics, bioscience, electronics, and English linguistics, etc.

Though different in backgrounds concerning gender, nationality, age, specialty, or degrees, they had similar language proficiency in common. In other words, on the one hand, they were high-proficient English users in that English was required in their master or doctor application and accordingly is their main medium of instruction in the study. On the other hand, they were low-proficient Korean users since they paid no or little attention to the Korean language study before going to this university. What is worse, since they studied and lived in a Korean dominant environment, it is inevitable for them to suffer the "headache" of language problems although nearly all of them learned Korean all by themselves or attended to language centers irregularly. However, admittedly, they were exposed to an atmosphere where both oral and visual Korean language were available from various sources and may aid their Korean learning to a certain degree.

\section{B. Instrument}

For this small-scale case study, a questionnaire was adopted as the main instrument for quantitative research. The questionnaire was developed by the two authors on the basis of the reviews of the literature pertaining to perception, attitude, and practice of the LL used as an additional source for language learning. The questionnaire consisted of two parts, one of which was the demographic information, and the other of which included 12 questions regarding their perception, attitude, and practice of the LL. All the questions were measured by a 5-point Likert scale ranging from 1 point (strongly disagree) to 5 points (strongly agree). Table one is detailed information about the questionnaire. It should be noted that since all the subjects were newcomers of lower Korean proficiency, all the questions were simple and basic especially for language practice (which only included the level of pronunciation, word, grammar, and general information gaining), which are shown in Table 1.

TABLE I.

TOPICS AND QUESTIONS OF THE QUESTIONNAIRE

\begin{tabular}{cl}
\hline Topic & Question \\
\hline Perception & I often see the LL (signages, road names, shop names, posters, notice, etc.) around. \\
& I read the Korean language more than other languages. \\
& I read the English language more than other languages. \\
& I read the Romanized Korean (e.g. Daehak-ro for 대학로) more than other languages. \\
Attitude & I think long and complicated Korean LL waste my time. \\
& I think long and complicated Korean LL is difficult for me to understand. \\
& I think the Korean language on the LL is an authentic input to enhance my Korean learning. \\
Practice & I spontaneously use the Korean language on the LL to practice my pronunciation of Korean when I see it. \\
& I spontaneously use the Korean language on the LL to enrich my vocabulary of Korean when I see it. \\
& I spontaneously use the Korean language on the LL to check my grammar understanding of Korean when I see it. \\
& I read the LL to get information. \\
& I use an electronic dictionary or translation apps to help me understand the information. \\
\hline
\end{tabular}

\section{Procedure}

Exemplified by many scholars, pilot test is with remarkable magnitude in the refinement of questionnaires previous to formal survey in order to examine potential errors and enhance validity (Churchill, 1979; Hussey \& Hussey, 1997). Due to the reason that errors might be related to the layout and question clarity, the primary purpose of pilot study is to acquire advice from respondents with respect to the design of questionnaires so that the completion of survey in the future study will be simplified and the bias can be lessened.

In order to validate the selection of the proper instruments measuring the perception, attitude and practice of LL by Korean language beginners, the author of the current study did a pilot test with a small number of 10 international undergraduates from the same university. The respondents were asked to help the author test the validity and reliability of the items included in the questionnaire, and more importantly, reduce ambiguous or misleading attributes to achieve comprehensive understanding of the questionnaire and improve the level of relevancy and accuracy. Afterwards, the questionnaire was refined accordingly and sent to the third author and one extra EFL professors for validity verification. The final refined paper-and-pencil questionnaires were then distributed to the target 41 participants with their consent and acknowledgment that their responses to the questionnaire will only be used for academic purposes in this study and all the demographic information will be kept in confidential. After data collection, the collected data were input manually into SPSS Statistics 24 for further descriptive analysis.

\section{RESULTS AND DISCUSSION}

This study concentrated on the low-proficient international students, who were accordingly the only specific group without comparing with other groups. Therefore, the results were shown in descriptive statistics by comparing with the pre-set 5-point Likert scale (Strongly Disagree=1, Disagree=2, Neutral=3, Agree=4, and Strongly Agree=5).

\section{A. What Language Will the International Students Pay Attention to More (Most)?}


In South Korea, languages on the LL include different languages including Korean, English, Chinese, and Japanese, etc. In this study, considering the background of the international students and the prevalence of languages, only three commonly used language forms were included, namely the official language Korean, the Romanized version of Korean, and the lingua franca English (Crystal, 2003).

In general, as is indicated in Table 2, these 41 international students agreed that they could often see the LL with a mean score of 3.71. Based on the visibility of the LL, their perception of the languages on the LL varied from the highest of reading English $(M=3.61)$ to the lowest of reading Romanized Korean $(M=2.54)$. It should be noted that their perception of English exceeded the average line of 3 points, indicating that English was the language that they paid attention to the most. In contrast, Korean $(\mathrm{M}=2.80)$ gained relatively lower attention, followed by the Romanized Korean $(\mathrm{M}=2.54)$, the lowest.

TABLE II.

PERCEPTION OF LINGUISTIC LANDSCAPE

\begin{tabular}{cc}
\hline Perception & Mean (SD) \\
& $\mathrm{N}=41$ \\
\hline See the LL & $3.71(.844)$ \\
Read Korean & $2.80(1.269)$ \\
Read English & $3.61(1.159)$ \\
Read Romanized Korean & $2.54(.977)$ \\
\hline
\end{tabular}

Statistically, English was paid the most attention among the three language forms. However, it is easy to understand why it was so. For these international students living and studying in a foreign country, English was the main tool for them to communication and study, and when there was no mother tongue available, English automatically became the only choice. In this study, English on the LL could not be regarded as a source of language learning since they were already high-level English users. The only possibility for them to focus on English on the LL is to get information (to solve practical problems like getting the name of a road or a shop, to get informed of warning or notice, etc.) which is confirmed by the result demonstrated in Table 4 where there was a high score on reading the LL to get information $(\mathrm{M}=3.61)$.

Though relatively low in the perception of Korean and Romanized Korean, it does not mean the LL could not be a source for Korean learning. Gorter \& Cenoz (2015), by broadening the differentiation between an informative and a symbolic function of the LL (Landry \& Bourhis, 1997), classified the languages or subject content on the LL as an informative function. In other words, through the process of getting information on the LL, the perceivers can automatically acquire language. Hence, it is reasonable to say that the international students in this study could use the LL as a potential source of language learning (Cenoz \& Gorter, 2008), in way of "incidental learning” (Kim, 2017, p.69).

\section{B. What Is Their Attitude toward the LL as Authentic Input to Learn the Korean Language?}

The attitude towards the use of the LL as authentic input for Korean learning is on the following consideration. If the students do not deny the use of long and complicated Korean LL, it can lead to a reasonable conclusion that they will definitely be positive to such short and simple ones as road name signs, notices, or shop name signs. Therefore, in this survey, these international students were provided the questions in terms of the length and complicacy of the LL.

Table 3 shows their attitudes to long and complicated LL. It is clear that, for these students, they had a high agreement with the difficulties of long and complicated LL $(M=3.71)$. However, they were more tolerant of the time spent in reading long and complicated LL $(M=2.71)$. As such, their attitude to the LL as input for Korean learning went over the average line, reaching a relatively high point $(\mathrm{M}=3.51)$.

TABLE III.

ATTITUDES TOWARDS LINGUISTIC LANDSCAPE

\begin{tabular}{cc} 
& ATTITUDES TOWARDS LINGUISTIC LANDSCAPE \\
\hline Attitude & $\frac{\text { Mean (SD) }}{\mathrm{N}=41}$ \\
\hline Korean waste time & $2.71(1.006)$ \\
Korean difficult & $3.71(.929)$ \\
Authentic input & $3.51(.771)$ \\
\hline
\end{tabular}

For the low-proficient Korean users, it is not surprising to feel difficult in reading long and complicated LL. However, it is surprising that they did not think reading such LL would waste their time. This can be possibly explained by drawing into the use of an electronic dictionary or translation apps. As a result, when asked the general attitude to the use of the LL as authentic input for language learning, they acted positively. This finding is in line with the previous studies by Gorter \& Cenoz (2004) and Cenoz \& Gorter (2011), which surely proves the possibility of the LL for Korean learning from the perspective of attitude.

\section{What Do They Do with LL to Aid Their Korean Language Learning?}

Taking into account the fact that these international students were newcomers in an unfamiliar environment with lower Korean ability, this study did not cover such topics that Cenoz \& Gorter (2008) suggested as pragmatic 
competence or multi-competence but included very basic linguistic abilities in terms of pronunciation, vocabulary, and grammar. Besides, the purpose of their noticing the LL and the strategy of using the electronic dictionary or translation apps were included for self-assessment.

Table 4 presents the results of what they did when paying attention to the LL. It is clear that from the linguistic perspective, they made more use of the LL to practice pronunciation $(M=3.39)$ and enrich the vocabulary $(M=3.17)$; however, checking grammar was relatively low $(M=2.88)$. In terms of the function or purpose of their reading the LL, they showed a high agreement that they read the LL to get information $(M=3.61)$. What is more, electronic dictionary or translation apps play a very important role in their reading of the LL $(\mathrm{M}=3.90)$.

TABLE IV.

PRACTICE OF THE LINGUISTIC LANDSCAPE IN LEARNING

\begin{tabular}{cc}
\hline Practice & $\frac{\text { Mean }(\mathrm{SD})}{\mathrm{N}=41}$ \\
\hline Practice pronunciation & $3.39(.082)$ \\
Enrich vocabulary & $3.17(.834)$ \\
Check grammar & $2.88(.812)$ \\
Get information & $3.61(.833)$ \\
Use Dictionary & $3.90(1.068)$ \\
\hline
\end{tabular}

The features of the Korean language may explain the different degrees to the practice of the LL. First, Korean is a phonogram which means that each character corresponds to a specific sound so that it is easier for the speakers to manage abundant sounds of a language. Therefore, it is natural for any learners in Korea to follow the phonogram to practice their pronunciation. As to vocabulary, there are many loanwords in Korean vocabulary borrowing from other languages, when noticing the LL, it is possible for these international students to compare or associate a Korean word with their native language or English. On the contrary, the lower score of grammar checking may be due to the relatively complex Korean grammar system where there are language peculiar particles, changeable verb endings and various connectors, which of course, could be a headache for these new Korean beginners.

Different from the previous studies reviewed where the LL as mediation in certain experiments to facilitate language-related study, this study was more a self-assessment of these lower proficiency Korean users. The simple and basic questions regarding the practice of pronunciation, increasing vocabulary, and grammar learning were by no means a summary of their practice with the LL. In other words, their performance with LL made the LL in fact as an effective way of their language learning. What is more, by using electronic dictionary or translation apps to deal with difficulties on LL, they could extend and consolidate their instant Korean learning.

\section{CONCLUSION}

With a simple and basic questionnaire, this study portrayed a general view of the Korean language learning situation of a particular group of international students. The descriptive statistics from their self-assessment uncovered that first they noticed the LL around them and paid attention to English the most, followed by Korean and Romanized Korean which could be a potential source for their Korean learning. Their positive attitude to the LL as authentic input was also confirmed. What is more, in terms of linguistic ability, they frequently made use of the LL to practice pronunciation, enrich their Korean vocabulary and at times checked their Korean grammar.

Admittedly, this study is small-scaled with a limited number of participants involved. However, just because of the availability of admission for international students with certain English language to South Korean universities, this so-called "weak" group exists in nearly every Korean university and they cannot be neglected. This study, for practical use, opened a door to perceive how these students made use of LL in their Korean language learning. At the same time, for theoretical use, this study contributed to verifying the previous studies about the use of LL in language learning. Again, it should be noted that this study was conducted in an informal setting where no language teachers mediated with an LL-related treatment or help. The result showed that in natural settings, the international students, who were seen as "weak" in studying and living in a totally unfamiliar environment could also survive themselves in the language aspect by using the LL as an additional and useful tool.

\section{ACKNOWLEDGEMENTS}

I would like to thank Zhang Heng who has made fundamental contributions to the research. This research would have been impossible to carry out without his participation and support. Also, I would like to give my sincere thanks to Professor Nadezda Sorokina for her vital guidance and instructions. They have been making significant efforts during the whole research process and have showed great kindness and patience.

\section{REFERENCES}

[1] Cenoz, J. \& D. Gorter. (2008). The linguistic landscape as an additional source of input in second language acquisition. IRAL-International Review of Applied Linguistics in Language Teaching 46.3, 267-287.

[2] Cenoz, J., \& D. Gorter. (2011). The perception of the linguistic landscape by students in two multilingual contexts. Uporabno 
Jezikoslovje/Applied Linguistics Journal of the Slovenian Association of Applied Linguistics 9.10, 264-279.

[3] Chesnut, M., V. Lee \& J. Schulte. (2013). The language lessons around us: Undergraduate English pedagogy and linguistic landscape research. English Teaching: Practice and Critique 12.2, 102-120.

[4] Churchill, J., G. A. (1979). A paradigm for developing better measures of marketing constructs. Journal of Marketing Research 16.1, 66-73.

[5] Clemente, M., A.I. Andrade \& F. Martins. (2012). Learning to read the world, learning to look at the linguistic landscape: A primary school study. In C. Hélot, M. Barni, R. Janssens \& C. Bagna (eds.), Linguistic landscapes, multilingualism and social change. Frankfurt: Peter Lang, 267-285.

[6] Crystal, D. (2003). English as a global language (2nd edn). Cambridge, UK: Cambridge University Press.

[7] Dagenais, D., D. Moore, C. Sabatier, P. Lamarre \& F. Armand. (2009). Linguistic landscape and language awareness. In E. Shohamy \& D. Gorter (eds.), Linguistic landscape: Expanding the scenery. London, UK: Routledge, 253-269.

[8] Dörnyei, Z. (1997). Motivational factors in second language attainment: A review of research in Hungary. Acta Linguistica Hungarica 44.3, 261-275.

[9] Gorter, D. \& J. Cenoz. (2004). Linguistic landscapes and L2 learners in multilingual contexts. Paper at EUROSLA 14 (European Second Language Association Conference), 8-11 September 2004, San Sebastian/Donostia, Basque Country, Spain.

[10] Gorter, D. \& J. Cenoz. (2015). The linguistic landscapes inside multilingual schools. In B. Spolsky, M. Tannenbaum, O. Inbar (eds.), Challenges for language education and policy: Making Space for People. New York: Routledge Publishers, 151-169.

[11] Gorter, D. (2018). Linguistic landscapes and trends in the study of schoolscapes. Linguistics and Education 44.3, 80-85.

[12] Hussey, J. \& R. Hussey. (1997). Business research. Hampshire, UK: Macmillian Business.

[13] Kim, S. (2017). Linguistic landscape in pre-service teacher education: Potentials and considerations. Multimedia-Assisted Language Learning 20.4, 66-98.

[14] Landry, R. \& R. Bourhis. (1997). Linguistic landscape and ethnolinguistic vitality: An empirical study. Journal of Language and Social Psychology 16.3, 24-27.

[15] Malinowski, D. (2010). Showing seeing in the Korean linguistic cityscape. In E. Shohamy, E. Ben-Rafael \& M. Barni (eds.), Linguistic landscape in the city. Bristol: Multilingual Matters, 199-215.

[16] Min-seo, K. \& M. Kim. Number of international students rises to all-time high in South Korea. https://pulsenews.co.kr/view.php?year=2019\&no=680611 (accessed 20/6/2020).

[17] Rowland, L. (2013). The pedagogical benefits of a linguistic landscape project in Japan. International Journal of Bilingual Education and Bilingualism 16.4, 494-505.

[18] Sayer, P. (2010). Using the linguistic landscape as a pedagogical resource. ELT Journal 64.2, 143-154.

[19] Shohamy, E. \& D. Gorter. (2009). Linguistic landscape: Expanding the scenery. London UK: Routledge.

[20] Van Mensel, L., M. Vandenbroucke \& R. Blackwood (2016). Linguistic landscapes. In O. Garcia, N. Flores \& M. Spotti (eds.), The Oxford handbook of language and society. Oxford: Oxford University Press, 423-500.

Wenjin Qi is currently a $\mathrm{PhD}$ candidate at Woosong University, South Korea. She received her Master degree of Social Linguistics in National Technological University (Singapore) in 2016. Her research interests include English language learning and teaching, interdisciplinary study of social semiotics in tourism discourse, and teacher education.

Heng Zhang is currently a PhD candidate in English Linguistics and a lecturer at Nanchang Normal University, Jiangxi, China. He is also an English counselor providing professional development to EFL teachers around the local areas. His research interest covers sociolinguistics, semantics, and pragmatics.

Nadezda Sorokina is an assistant professor of Hospitality \& Tourism Management in Sol International Hospitality Management (SIHOM), Woosong University, South Korea. Her research interest covers medical tourism, social semiotics in marketing, and education. 